\title{
Analisis Pengaruh Temperatur Pemanasan Terhadap Sifat Fisis Sinter Silika dan Tipe Fluida (Air) pada Mata Air Panas Sapan Maluluang, Kecamatan Alam Pauh Duo, Kabupaten Solok Selatan
}

\author{
Tania Dian Putri*, Ardian Putra \\ Laboratorium Fisika Bumi, Jurusan Fisika, \\ Fakultas Matematika dan Ilmu Pengetahuan Alam Universitas Andalas \\ Kampus Unand Limau Manis, Padang, 25163, Indonesia \\ *taniadianputri@gmail.com, ardhee@fmipa.unand.ac.id
}

\begin{abstract}
ABSTRAK
Telah dilakukan analisis sifat fisis sinter silika dan tipe fluida pada mata air panas Sapan Maluluang Kecamatan Alam Pauh Duo, Solok Selatan. Sifat fisis yang diteliti dalam penelitian ini yaitu densitas dengan menggunakan hukum Archimedes, porositas dengan menggunakan standar ASTM D7263-09 (Standard Test Methods for Laboratory Determination of Density of Soil Specimens), dan resistivitas dengan metode Probe Dua Elektroda. Nilai densitas, porositas dan resistivitas sinter silika pada temperatur $31^{\circ} \mathrm{C}$ dalam pengukuran ini adalah $1,206 \mathrm{~g} / \mathrm{cm}^{3}, 15,8 \%$, dan $7,195 \Omega \mathrm{m}$. Pengaruh temperatur terhadap sifat fisis sinter silika juga dianalisis dalam penelitian ini. Berdasarkan pengukuran, peningkatan temperatur dari $175{ }^{\circ} \mathrm{C}$ hingga $300{ }^{\circ} \mathrm{C}$ mengakibatkan nilai densitas turun dari $1,112 \mathrm{~g} / \mathrm{cm}^{3}$ menjadi 0,983 $\mathrm{g} / \mathrm{cm}^{3}$, sedangkan nilai porositas sinter silika naik dari 33,3\% menjadi 53,3\%. Nilai resistivitas sinter silika juga mengalami peningkatan dari 23,035 $\Omega \mathrm{m}$ menjadi 57,201 $\Omega \mathrm{m}$. Terdapat hubungan nilai faktor resistivitas dengan porositas yaitu bertambahnya pori-pori sinter silika mengakibatkan nilai faktor resistivitas mengecil. Hubungan nilai faktor resistivitas dan porositas sinter silika menghasilkan nilai sementasi dan tortuositas sinter silika. Meningkatnya temperatur sinter silika dari $175{ }^{\circ} \mathrm{C}$ hingga $300{ }^{\circ} \mathrm{C}$ menyebabkan nilai tortuositas meningkat dari 6,92 menjadi 48,89 dan sementasi mengecil dari 1,67 menjadi 1,08. Penentuan tipe fluida mata air panas, menggunakan kandungan sulfat, klorida dan bikarbonat yang terdapat pada air panas. Metode yang digunakan dalam pengujian kandungan sulfat yaitu Spektrofotometri, sedangkan kandungan klorida dan bikarbonat diuji dengan metode Argentometri cara Mohr dan metode titrasi asam basa. Berdasarkan pengolahan data menggunakan diagram trilinier, mata air panas Sapan Maluluang termasuk kedalam tipe air panas klorida karena kandungan klorida merupakan kandungan yang paling dominan yaitu mencapai 97,560 mg/L, sedangkan kandungan sulfat dan bikarbonat mencapai $21,333 \mathrm{mg} / \mathrm{L}$ dan $23,730 \mathrm{mg} / \mathrm{L}$.
\end{abstract}

Kata kunci : densitas, porositas, resistivitas, sinter silika, tipe air panas

ABSTRACT

Physical properties silica sinter and fluid content of hot springs Sapan Maluluang, Solok Selatan has been analyzed. Physical properties were examined in this study are density using Archimedes law, porosity using the standard ASTM D7263-09 (Standard Test Methods for Laboratory Determination of Density of Soil Specimens), and resistivity silica sinter With Two Electrode Probe method. The density, porosity and resistivity silica sinter at temperature of $31^{\circ} \mathrm{C}$ on this measurement is $1,206 \mathrm{~g} / \mathrm{cm}^{3}, 15,8 \%$, and 7,195 $\Omega \mathrm{m}$. The influence of temperature on the physical properties of the silica sinter was analyzed in this research. Based on the measurements, the increased temperature of $175{ }^{\circ} \mathrm{C}$ to $300{ }^{\circ} \mathrm{C}$ resulted density values are $1,112 \mathrm{~g} / \mathrm{cm}^{3}$ decreased to $0,983 \mathrm{~g} / \mathrm{cm}^{3}$, while porosity silica sinter rose from $33.3 \%$ to $53.3 \%$. Silica sinter resistivity values also increased from 23,035 $\Omega$ m into 57,201 $\Omega$ m. There is a relationship with a porosity value of the formation resistivity, in which increasing pore silica sinter resulted in the formation resistivity value decreases. Relationship value formation resistivity and porosity of the silica sinter will get value cementation and tortuosity silica sinter. Effect of silica sinter temperature of $175^{\circ} \mathrm{C}$ to $300^{\circ} \mathrm{C}$ causes increasing of tortuosity value of 6,92 into 48,89 and cementation smaller from 1,67 to 1,08. This research also determine the fluid type hot springs in the form of sulphate, chloride and bicarbonate. The method used in testing the content of sulfate is spectrophotometry, while the content of chloride and bicarbonate were measured by the method Argentometry Mohr and acid-base titration method. Based on the data processing using Trilinear diagram, hot springs Sapan Maluluang included into the hot water type chloride, because the content of chloride is greatest content of 97,560 $\mathrm{mg} / \mathrm{L}$, while the content of sulfate and bicarbonate reached $21,333 \mathrm{mg} / \mathrm{L}$ and 23,730 $\mathrm{mg} / \mathrm{L}$.

Keywords: density, porosity, resistivity, silica sinter, type of hot spring 


\section{PENDAHULUAN}

Sistem panas bumi dapat ditandai dengan munculnya manifestasi panas bumi berupa fluida yang berasal dari dalam bumi dan muncul di permukaan melalui patahan atau batuan permeabel. Manifestasi panas bumi dapat berupa mata air panas dan endapan yang terdapat di sekitar mata air panas (Saptadji, 2002).

Fluida mata air panas umumnya terdiri atas tiga tipe yaitu tipe air sulfat, bikarbonat dan klorida. Setiap tipe air panas memiliki karakteristik reservoir yang berbeda-beda. Karakteristik reservoir berupa temperatur reservoir tinggi dan berada pada kedalaman yang dalam ditandai dengan mata air panas yang mengandung klorida yang tinggi atau termasuk ke dalam tipe air klorida, sedangkan air panas yang mengandung dominan sulfat biasanya juga memiliki temperatur tinggi dan dikontrol oleh kegiatan vulkanik aktif sehingga uap terkondensasi menjadi air permukaan. Tipe air panas bikarbonat merupakan hasil dari kondensasi uap air dan gas yang berada di bawah permukaan dengan kandungan oksigen yang sedikit, berada di daerah non vulkanik dan memiliki sistem temperatur sedang (Nicholson, 1993).

Air panas yang berasal dari reservoir mengalir sampai ke permukaan bumi mengandung berbagai mineral seperti silika, kalsium, belerang, litium, dan radium. Mineral yang terbawa oleh aliran mata air panas akan mengendap di permukaan bumi. Endapan ini dapat berupa sinter, salah satunya yaitu sinter silika. Sinter silika merupakan manifestasi panas bumi dari fluida mata air panas yang berasal dari reservoir panas bumi mempunyai cukup silika dan mengendap jika suhu menurun hingga $50{ }^{\circ} \mathrm{C}$ (Wohltz dan Heiken, 1992).

Metode geofisika yang umumnya digunakan untuk menggambarkan kondisi panas bumi termasuk seismik, listrik dan radar memerlukan pengetahuan kecepatan seismik, densitas dan resistivitas listrik sinter untuk menafsirkan data geofisika (Saez, 2016). Bentuk dan ukuran pori-pori di lapisan sinter silika memberikan informasi tentang laju aliran fluida di bawah permukaan. Sifat fisik dan hidrolik batuan sangat dipengaruhi oleh struktur pori dan porositas batuan (Lynne, 2012).

Berdasarkan Hukum Archie (1942), hubungan resistivitas dengan porositas sinter silika akan menghasilkan nilai sementasi dan tortuositas sinter silika. Apabila sinter silika dipanaskan maka akan merubah sifat fisis (densitas, porositas dan resistivitas) dari sinter silika, sehingga nilai sementasi dan tortuositas sinter silika juga akan berubah.

\section{METODE}

Penelitian ini dimulai pada bulan Februari hingga Oktober 2016. Lokasi yang akan menjadi objek penelitian adalah mata air panas daerah Sapan Maluluang, Kecamatan Alam Pauh Duo, Kabupaten Solok Selatan.

\subsection{Uji Sifat Fisis Sinter Silika}

Pengujian sifat fisis sinter silika yang diuji pada penelitian ini adalah densitas, porositas dan resistivitas sinter silika. Berikut langkah pengujian sifat fisis sinter silika:

\subsubsection{Densitas Sinter Silika}

Langkah-langah yang dilakukan untuk pengujian densitas sinter silika yaitu sinter silika dipanaskan dalam Furnace dengan temperatur $31^{\circ} \mathrm{C}$ selama 3 jam. Setelah dipanaskan, sinter silika didinginkan hingga temperatur ruang. Kemudian massa sinter silika kering $\left(M_{k}\right)$ diukur dengan menggunakan timbangan. Lalu sinter silika dijenuhkan dalam air hingga kondisi jenuh. Kemudian dihitung volumenya dengan mengurangi volume air yang berisi sinter silika dengan volume air sebelum dimasukan sinter silika. Nilai densitas sinter silika dapat dihitung menggunakan Persamaan 1. Variasi temperatur yang digunakan pada pengujian densitas sinter silika adalah $175^{\circ} \mathrm{C}, 200^{\circ} \mathrm{C}, 225^{\circ} \mathrm{C}, 250^{\circ} \mathrm{C}, 275^{\circ} \mathrm{C}$, dan $300^{\circ} \mathrm{C}$.

$$
\rho=\frac{M_{k}}{V}
$$


dengan $\rho$ adalah massa jenis $\left(\mathrm{kg} / \mathrm{m}^{3}\right)$, sedangkan $M k$ adalah massa sampel $(\mathrm{kg})$ dan $V$ adalah volume sampel $\left(\mathrm{m}^{3}\right)$.

\subsubsection{Porositas Sinter Silika}

Pengukuran porositas sinter silika dapat dilakukan dengan cara yaitu sinter silika dipanaskan dalam Furnace dengan temperatur $31{ }^{\circ} \mathrm{C}$ selama 3 jam. Setelah dipanaskan, sinter silika didinginkan hingga temperatur ruang. Massa sinter silika kering $\left(M_{k}\right)$ diukur dengan timbangan. Kemudian sampel sinter silika diukur massanya dalam air $\left(M_{a}\right)$. Selanjutnya, diukur massa basah sinter silika $\left(M_{b}\right)$ dengan timbangan. Nilai porositas dapat dihitung dengan menggunakan Persamaan 2 berdasarkan standar ASTM D7263-09. Variasi temperatur digunakan untuk uji porositas sinter silika pada sampel yang sama dengan temperatur $175^{\circ} \mathrm{C}$, $200^{\circ} \mathrm{C}, 225^{\circ} \mathrm{C}, 250^{\circ} \mathrm{C}, 275^{\circ} \mathrm{C}$, dan $300^{\circ} \mathrm{C}$.

$$
\phi=\frac{M_{b}-M_{k}}{M_{b}-M_{a}} \times 100 \%
$$

dengan $\phi$ adalah porositas (\%), $M_{k}$ adalah massa kering (g), $M_{b}$ adalah massa basah (g), $M_{a}$ adalah massa sampel dalam air $(\mathrm{g})$.

\subsubsection{Resistivitas Sinter Silika}

Langkah-langkah dalam pengujian resistivitas sinter silika adalah sinter silika terlebih dahulu digerus, lalu dipanaskan dalam Furnace pada suhu $31{ }^{\circ} \mathrm{C}$ hingga 3 jam. Sinter silika yang telah dipanaskan kemudian didinginkan hingga temperatur ruang, kemudian dimasukkan ke dalam pipa PVC yang berisi sampel air panas yang telah diukur konduktivitas listriknya dengan konduktivitimeter. Sinter silika yang terdapat dalam pipa PVC kemudian direndam dalam air sampai kondisi jenuh. Sampel yang ada di dalam pipa PVC kemudian disusun sedemikian rupa pada rangkaian probe dua elektroda. Lalu gunakan sumber tegangan sebesar 1-10 V, didapat nilai arus (I), Panjang dan diameter sampel dalam pipa PVC diukur dan dihitung luas penampang sampel. Resistivitas pada sampel dihitung dengan menggunakan Persamaan 3. Variasi temperatur dilakukan pada setiap sampel. Temperatur yang digunakan adalah $175^{\circ} \mathrm{C}, 200{ }^{\circ} \mathrm{C}, 225^{\circ} \mathrm{C}, 250^{\circ} \mathrm{C}, 275^{\circ} \mathrm{C}$ dan $300^{\circ} \mathrm{C}$.

$$
\rho=\frac{V A}{I L}
$$

dengan $\rho$ adalah resistivitas $(\Omega \mathrm{m}), V$ merupakan beda potensial $(\mathrm{V})$ dan $I$ adalah arus yang mengalir, $A$ adalah luas penampang $\left(\mathrm{m}^{2}\right)$ dan $L$ adalah panjang sampel (m).

\subsection{Pengujian kandungan fluida (Air)}

Dalam menentukan tipe fluida (air) pada mata air panas dalam penelitian dilakukan pengukuran banyaknya kandungan sulfat, klorida dan bikarbonat yang terdapat dalam sampel.

\subsubsection{Uji Kandungan Klorida}

Pengujian kandungan klorida ini menggunakan metode titrasi Argentometri cara Mohr. Langkah-langkah untuk menentukan kandungan klorida adalah $100 \mathrm{~mL}$ sampel air panas dimasukkan ke dalam erlemeyer. kemudian ditambahkan 3-5 tetes larutan $\mathrm{K}_{2} \mathrm{CrO}_{4} 10 \%$. Selanjutnya, dititrasi dengan larutan $\mathrm{AgNO}_{3}$ 1/35,45 $\mathrm{N}$ hingga terjadi endapan merah bata. Volume larutan $\mathrm{AgNO}_{3}$ 1/35,45 $\mathrm{N}$ yang digunakan dicatat. Kandungan klorida dalam sampel air panas dapat dihitung menggunakan persamaan 4 .

$$
C l=\left(\frac{1000}{V s}\right) \times(T-0,3)+\left(\frac{10}{T}\right)
$$


dengan $C l$ yaitu banyaknya kandungan klorida dalam sampel $(\mathrm{mg} / \mathrm{L}), V s$ adalah volume sampel (mL), dan $T$ adalah volume AgNO3 yang digunakan dalam mentitrasi sampel hingga membentuk endapan merah bata $(\mathrm{mL})$.

\subsubsection{Uji Kandungan Sulfat}

Pengujian kandungan sulfat digunakan alat spektrofotometer merk Cole Parmer Tipe 1100 RS. Metode yang digunakan pada pengujian ini adalah metode spektrofotometri. Pengujian kandungan sulfat dilakukan dengan langkah-langkah yaitu larutan standar dibuat dengan konsentrasi 10, 20, 30, 40, dan 50 ppm dengan menambahkan kristal $\mathrm{BaCl}_{2}$ dan $10 \mathrm{~mL}$ larutan salt acid lalu diaduk selama 5 menit. Sampel air panas juga diberi perlakuan sama dengan larutan standar. Larutan standar yang telah dibuat, diukur absorbansinya dengan menggunakan spektrofotometer. Hasil yang didapatkan kemudian diplot ke dalam kurva. Selanjutnya sampel diukur nilai absorbansinya. Hasil yang di dapatkan kemudian dihubungkan dengan persamaan kurva yang telah diplot berdasarkan nilai absorbansi larutan standar. Persamaan 5 dapat digunakan untuk menghitung kandungan sulfat dalam sampel

$$
y=a x+b
$$

dimana $x$ adalah banyaknya kandungan sulfat pada sampel mata air panas (mg/L), $y$ adalah nilai absorbansi sampel mata air panas yang didapat dari pengukuran menggunakan alat spektrometrokopi, $a$ dan $b$ adalah nilai yang didapat dari persamaan garis hubungan kandungan larutan standar sulfat dengan absorbansinya.

\subsubsection{Uji Kandungan Bikarbonat}

Untuk menentukan kadar bikarbonat dalam sampel mata air panas dilakukan dengan metode titrasi asam basa. Berikut langkah-langkah dalam pengujian kandungan bikarbonat dalam sampel yaitu air panas dimasukkan ke dalam gelas beker sebanyak $100 \mathrm{~mL}$, pH meter dimasukkan ke dalam gelas beker. Kemudian dititrasi dengan larutan $\mathrm{H}_{2} \mathrm{SO}_{4}$ sampai pH 4,5. Volume $\mathrm{H}_{2} \mathrm{SO}_{4}$ yang terpakai dalam proses titrasi dicatat. Persamaan 6 digunakan untuk menghitung kandungan bikarbonat dalam sampel fluida (air) mata air panas.

$$
\mathrm{HCO}_{3}{ }^{-}=-\frac{A \times N \times 50000}{V s}
$$

dimana $\mathrm{HCO}_{3}{ }^{-}$adalah banyaknya kandungan bikarbonat dalam sampel mata air panas (mg/L), $A$ adalah volume $\mathrm{H}_{2} \mathrm{SO}_{4}$ yang digunakan, $N$ adalah normalitas dari $\mathrm{H}_{2} \mathrm{SO}_{4}$, $V s$ adalah volume sampel mata air panas yang digunakan.

\section{HASIL DAN DISKUSI}

\subsection{Hasil Pengujian Sifat Fisis Sinter Silika}

\subsubsection{Hasil Pengujian Densitas dan Porositas Sinter Silika}

Berdasarkan pengukuran di laboratorium, nilai densitas sinter silika dapat terlihat pada Gambar 1. Nilai densitas sinter silika pada mata air panas Sapan Maluluang pada suhu $31^{\circ} \mathrm{C}$ memiliki nilai $1,206 \mathrm{~g} / \mathrm{cm}^{3}$. Terlihat pada Gambar 1 bahwa nilai densitas sinter silika turun seiring meningkatnya temperatur pemanasan. Hal ini dapat terlihat pada Gambar 1, setelah sinter silika dipanaskan pada temperatur pemanasan $175^{\circ} \mathrm{C}$ sinter silika berkurang menjadi $1,112 \mathrm{~g} / \mathrm{cm}^{3}$. Begitu pula setelah sinter silika dipanaskan pada temperatur pemanasan $200{ }^{\circ} \mathrm{C}$, $225{ }^{\circ} \mathrm{C}, 250{ }^{\circ} \mathrm{C} 275{ }^{\circ} \mathrm{C}$ dan $300{ }^{\circ} \mathrm{C}$. 


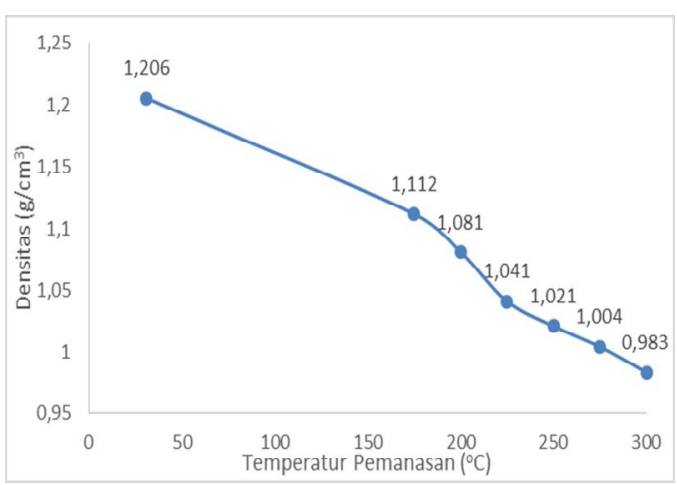

Gambar 1 Nilai Densitas Sinter Silika

Terlihat pada Gambar 2, nilai porositas sinter silika pada wilayah Sapan Malualuang pada temperatur $31^{\circ} \mathrm{C}$ mencapai $15,8 \%$. Nilai porositas sinter silika mengalami perubahan setelah sinter silika dipanaskan. Semakin besar temperatur pemanasan yang diberikan, nilai porositas sinter silika semakin besar. Hubungan ini dapat terlihat pada Gambar 2, sinter silika setelah dipanaskan dengan temperatur $175^{\circ} \mathrm{C}$, porositasnya meningkat sebesar menjadi $33,8 \%$. Nilai porositas sinter silika setalah dipanaskan pada temperatur $200{ }^{\circ} \mathrm{C}, 225^{\circ} \mathrm{C}, 250{ }^{\circ} \mathrm{C}, 275^{\circ} \mathrm{C}$ dan $300{ }^{\circ} \mathrm{C}$ juga terjadi peningkatan porositas.

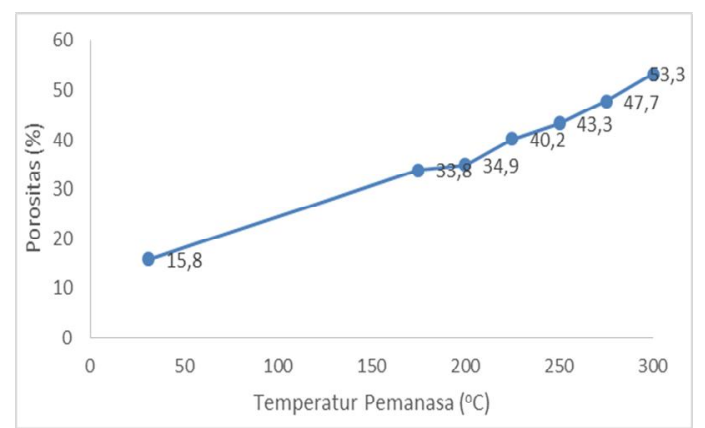

Gambar 2 Nilai Porositas Sinter Silika

Perubahan nilai densitas dan porositas sinter silika setelah dipanaskan disebabkan karena sinter silika mengalami pemuaian. Pemuaian adalah bertambahnya volume suatu benda ketika diberi pengaruh temperatur. Selain itu, fluida yang terdapat di sinter silika mengalami penguapan yang menyebabkan pori-pori yang terbentuk pada sinter silika semakin besar sehingga nilai rapat massa batuan semakin kecil.

\subsubsection{Hasil Pengujian Resistivitas Sinter Silika}

Berdasarkan hasil pengujian resistivitas sinter silika dengan metode Probe Dua Elektroda didapatkan pengaruh temperatur terhadap nilai resistivitas seperti Gambar 3. Semakin besar temperatur pemanasan yang diberikan nilai resistivitas semakin besar. Berdasarkan pengukuran resistivitas sinter silika pada temperatur $31^{\circ} \mathrm{C}$ didapatkan nilai resistivitas berkisar $7,195 \Omega$.m. Setelah sinter silika dipanaskan dengan temperatur pemanasan $175^{\circ} \mathrm{C}$, nilai resistivitas sinter silika bertambah menjadi $23,035 \Omega$.m. Terjadi peningkatan nilai resistivitas sinter silika setelah sinter silika dipanaskan dengan temperatur pemanasan $200^{\circ} \mathrm{C}, 225^{\circ} \mathrm{C}, 250$ ${ }^{\circ} \mathrm{C}, 275^{\circ} \mathrm{C}$ dan $300^{\circ} \mathrm{C}$. 


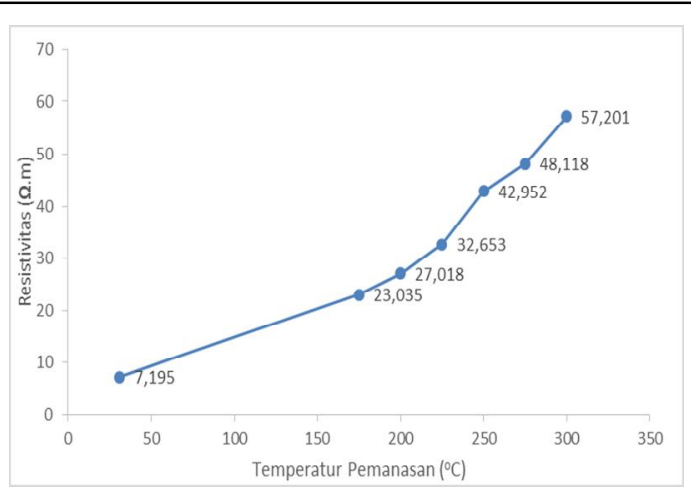

Gambar 3 Nilai Resistivitas Sinter Silika

Meningkatnya nilai resistivitas sinter silika seiring bertambahnya temperatur pemanasan ini dapat disebabkan oleh sinter silika yang mengalami pertambahan pori-pori setelah dipanaskan. Fluida yang terdapat pada sinter silika menguap sehingga terbentuk ruang kosong yang tidak dapat menghantarkan arus listrik.

\subsubsection{Hubungan Porositas dengan Resistivitas Sinter Silika}

Faktor resistivitas sinter silika memiliki hubungan dengan porositas sinter silika. Terlihat pada Gambar 4, nilai faktor resistivitas sinter silika pada temperatur $31^{\circ} \mathrm{C}$ mengecil seiring bertambahnya pori-pori batuan. Sifat listrik berupa resistivitas batuan tergantung pada geometri pori dan distribusi cairan (Saez, 2016). Archie (1942) menemukan hubungan empiris antara sifat listrik (faktor resistivitas) dan porositas yaitu $F_{R}=a \varphi^{-m}$ dengan $m$ adalah eksponen sementasi dengan nilai mendekati 2 , dan $a$ merupakan faktor tortuositas umumnya nilainya mendekati 1, dengan asumsi kondisi jenuh penuh.

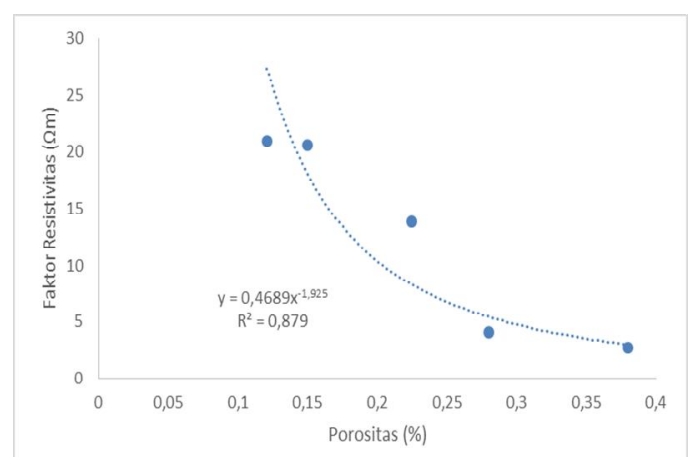

Gambar 4 Hubungan Faktor Resistivitas dan Porositas Sinter Silika Pada Temperatur $31^{\circ} \mathrm{C}$

Pada temperatur $31^{\circ} \mathrm{C}$, nilai $m$ atau sementasi sinter silika mencapai 1,9 . Nilai sementasi ini hampir sesuai dengan nilai yang ditetapkan oleh Hukum Archie yaitu bernilai 2. Nilai tortuositas yang bernilai 0,46 pada temperatur $31^{\circ} \mathrm{C}$ diperkirakan silika dalam keadaan jenuh dengan air, hal ini dikarenakan nilai tortuositas hampir mendekati 1.

Jika sinter silika diberi pengaruh temperatur pemanasan nilai sementasi dan tortuositas sinter silika menjadi berubah setelah dipanaskan atau setelah diberi pengaruh temperatur pemanasan. Terlihat pada Tabel 1 setelah sinter silika dipanaskan, nilai sementasi berkurang seiring bertambahnya temperatur pemanasan sedangkan nilai tortuositas bertambah seiring meningkatnya temperatur pemanasan.

Berdasarkan Tabel 1 hubungan faktor resistivitas dengan porositas sinter silika dalam mendapatkan nilai sementasi dan tortuositas setelah dipanaskan pada rentang di bawah temperatur $200^{\circ} \mathrm{C}$, hukum Archie $\left(F_{R}=a \varphi^{-m}\right)$ dapat berlaku. Hal ini dapat terlihat pada Tabel 1 nilai koefisien korelasi $(R)$ faktor resistivitas dengan porositas pada sinter silika setelah dipanaskan pada temberatur $175^{\circ} \mathrm{C}$ dan $200{ }^{\circ} \mathrm{C}$ adalah 0,94 dan 0,89 . Namun, pada temperatur tinggi atau diatas $200{ }^{\circ} \mathrm{C}$, hukum Archie kurang tepat dalam mendapatkan nilai tortuositas dan sementasi sinter silika. 
Tabel 1 Nilai Tortuositas, Sementasi Dan Koefisien Korelasi $(R)$ antara Faktor Resistivitas dan Porositas Sampel Sinter Silika Bergantung Temperatur Pemanasan

\begin{tabular}{cccc}
$\boldsymbol{T}_{\text {pemanasan }}$ & $\boldsymbol{A}$ & $\boldsymbol{m}$ & $\boldsymbol{R}$ \\
\hline 175 & 6,92 & 1,68 & 0,94 \\
200 & 8,96 & 1,66 & 0,89 \\
225 & 15,43 & 1,51 & 0,77 \\
250 & 24,57 & 1,39 & 0,53 \\
275 & 32,33 & 1,37 & 0,58 \\
300 & 48,90 & 1,08 & 0,36 \\
\hline
\end{tabular}

\subsection{Tipe Fluida Air Panas}

Berdasarkan hasil pengukuran kandungan sulfat, klorida dan bikarbonat pada sampel air panas Sapan Maluluang diketahui bahwa kandungan klorida adalah kandungan yang paling dominan pada sampel air panas yaitu mencapai $97,56 \mathrm{mg} / \mathrm{L}$. Sedangkan kandungkan sulfat dan bikarbonat yang terdapat pada sampel air panas Sapan Maluluang ini berkisar 23,730 mg/L dan $21,33 \mathrm{mg} / \mathrm{L}$.

Berdasarkan pengolahan data dalam diagram trilinier yang tertera pada Gambar 5 didapat bahwa mata air panas di daerah Sapan Maluluang termasuk kedalam tipe air klorida. Air panas klorida ini memiliki karakteristik berupa reservoir panas bumi berada kedalaman yang dalam dengan suhu sekitar $175^{\circ} \mathrm{C}$ serta terdapatnya endapan dominan silika (sinter silika) di sekitar mata air panas (Fournier and Rowe, 1966).

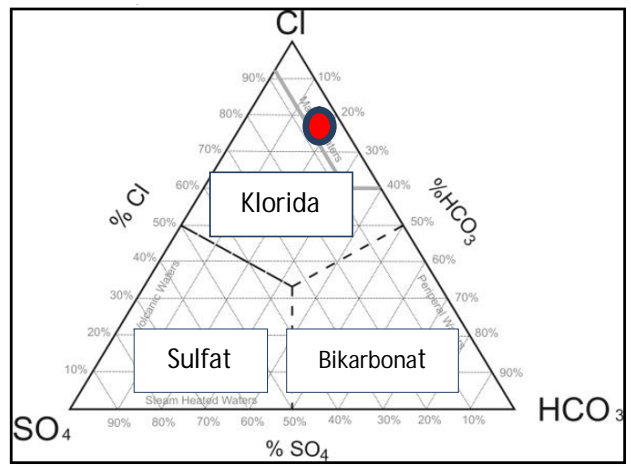

Gambar 5 Diagram Trilinier Tipe Air Panas

Jenis air dominan klorida ini merupakan tipe fluida panas bumi yang ditemukan pada kebanyakan area dengan sistem temperatur tinggi. Area yang memiliki mata air panas yang mengalir dalam skala besar dengan konsentrasi klorida yang tinggi berasal dari reservoir dalam, dan merupakan indikasi dari zona permeabel pada area tersebut. Namun, area ini mungkin juga tidak terletak di atas zona upflow utama, karena ada beberapa kemungkinan lain seperti pengaruh topografi yang juga dapat memberikan dampak besar dalam mengontrol hidrologi. (Emianto, 2011).

\section{KESIMPULAN}

Berdasarkan hasil pengujian dan perhitungan yang telah dilakukan terhadap 5 sampel yang diambil pada lokasi mata air panas di Kabupaten Solok Selatan, maka dapat disimpulkan yaitu nilai densitas, porositas dan resistivitas sinter silika pada temperatur $31^{\circ} \mathrm{C}$ mencapai 1,206 $\mathrm{g} / \mathrm{cm}^{3}, 15,8 \%$ dan $7,195 \Omega \mathrm{m}$. Semakin tinggi temperatur sinter silika maka nilai densitas semakin kecil, porositas dan resistivitas sinter silika semakin besar. Mata air panas Sapan Maluluang memiliki kandungan fluida dominan klorida yaitu mencapai 97,560 mg/L, sedangkan kandungan sulfat dan bikarbonat mencapai $21,333 \mathrm{mg} / \mathrm{L}$ dan 23,730 mg/L. Mata air panas ini termasuk ke dalam tipe klorida. 


\section{DAFTAR PUSTAKA}

Archie, G.E., The Electrical Resistivity Log As An Aid In Determining Some Reservoir Characteristics: Petroleum Transactions Of AIME (Am. Inst. Min. Metall. Eng., 1942), hal 54-62.

ASTM D7263-09, Standard Test Methods for Laboratory Determination of Density (Unit Weight) of Soil Specimens, ASTM International, (West Conshohocken, PA, 2009)

Emianto, Y, B, Jurnal Teknik, hal 231 (2011).

Fournier, R.O. dan Rowe, J.J., Journal Science 685-698 (1966).

Lynne, B.Y., Journal Geotermics, 3-24 (2012).

Nicholson, K., Geothermal Fluids, ( Springer Verlag, Inc., Berlin, 1993).

Saez, C., Journal of Volcanology and Geothermal Research 256, 156-158 (2016).

Saptadji, N. M., Teknik Panas Bumi, (Institut Teknologi Bandung, Bandung, 2002).

Wohletz, K. Dan Heiken, G., ., Journal of Volcanology and Geothermal Research, (1992). 